\title{
Microstructure and Mechanical Properties of Diffusion-Bonded CoCrNi-Based Medium-Entropy Alloy to DD5 Single-Crystal Superalloy Joint
}

\author{
Shiwei Li ${ }^{1,2}$, Xianjun Sun ${ }^{1,2}$, Yajie Du ${ }^{1,2}$, Yu Peng ${ }^{1,2}$, Yipeng Chen ${ }^{1,2}$, Zhaoxi Li ${ }^{1,2}$, Jiangtao Xiong ${ }^{1,2, *(\mathbb{D})}$ \\ and Jinglong $\mathrm{Li}^{1,2, *}$ \\ 1 State Key Laboratory of Solidification Processing, Northwestern Polytechnical University, Xi'an 710072, China; \\ lisw@mail.nwpu.edu.cn (S.L.); 2019260981@mail.nwpu.edu.cn (X.S.); duyajie@mail.nwpu.edu.cn (Y.D.); \\ pengyuyu@mail.nwpu.edu.cn (Y.P.); 2019200858@mail.nwpu.edu.cn (Y.C.); zxli@mail.nwpu.edu.cn (Z.L.) \\ 2 Shaanxi Key Laboratory of Friction Welding Technologies, Northwestern Polytechnical University, \\ Xi'an 710072, China \\ * Correspondence: xiongjiangtao@nwpu.edu.cn (J.X.); lijinglg@nwpu.edu.cn (J.L.)
}

check for

updates

Citation: Li, S.; Sun, X.; Du, Y.;

Peng, Y.; Chen, Y.; Li, Z.; Xiong, J.;

$\mathrm{Li}, \mathrm{J}$. Microstructure and Mechanical

Properties of Diffusion-Bonded

CoCrNi-Based Medium-Entropy

Alloy to DD5 Single-Crystal

Superalloy Joint. Crystals 2021, 11,

1127. https://doi.org/10.3390/

cryst11091127

Academic Editor: Cyril Cayron

Received: 27 August 2021

Accepted: 11 September 2021

Published: 16 September 2021

Publisher's Note: MDPI stays neutral with regard to jurisdictional claims in published maps and institutional affiliations.

Copyright: (c) 2021 by the authors. Licensee MDPI, Basel, Switzerland. This article is an open access article distributed under the terms and conditions of the Creative Commons Attribution (CC BY) license (https:// creativecommons.org/licenses/by/ $4.0 /)$.

\begin{abstract}
This study focuses on the diffusion bonding of a CoCrNi-based medium-entropy alloy (MEA) to a DD5 single-crystal superalloy. The microstructure and mechanical properties of the joint diffusion-bonded at variable bonding temperatures were investigated. The formation of diffusion zone, mainly composed of the $\mathrm{Ni}_{3}(\mathrm{Al}, \mathrm{Ti})$-type $\gamma^{\prime}$ precipitates and Ni-rich MEA matrix, effectively guaranteed the reliable joining of MEA and DD5 substrates. As the bonding temperature increased, so did the width of the diffusion zone, and the interfacial microvoids significantly closed, representing the enhancement of interface bonding. Both tensile strength and elongation of the joint diffusionbonded at $1110^{\circ} \mathrm{C}$ were superior to those of the joints diffusion-bonded at low temperatures (1020, 1050 , and $1080^{\circ} \mathrm{C}$ ), and the maximum tensile strength and elongation of $1045 \mathrm{MPa}$ and $22.7 \%$ were obtained. However, elevated temperature produced an adverse effect that appeared as grain coarsening of the MEA substrate. The ductile fracture of the joint occurred in the MEA substrate $\left(1110{ }^{\circ} \mathrm{C}\right)$, whereas the tensile strength was lower than that of the MEA before diffusion bonding (approximately $1.3 \mathrm{GPa}$ ).
\end{abstract}

Keywords: microstructure; mechanical properties; medium-entropy alloy; single-crystal superalloy; diffusion bonding

\section{Introduction}

High-entropy alloys (HEAs), consisting of four or more elements with each concentration between 5 and 35 at.\%, exhibit various composition designs, interesting phase transformations, and noble properties. HEAs have been receiving extensive research focus since the conception of HEA was proposed [1-3]. Among these, HEAs with a face-centered cubic (FCC) structure, represented by the CoCrFeMnNi family, have been attracting the most attention during the past decade [4,5]. CoCrNi medium-entropy alloys (MEAs) with low stacking fault energy (SFE) were optimized from CoCrFeMnNi HEAs. The MEAs present a superior combination of strength and ductility because of nanoscale twins promoting plasticity and continuous hardening [6-8]. Furthermore, CoCrNi-based MEAs containing coherent nanoscale $\gamma^{\prime}$ phase with an L12 superlattice structure, namely ordered FCC structure, are potentially advantageous materials to compete with commercial superalloys [9,10]. According to An et al. [10], a CoCrNi-based MEA composed of $\mathrm{Ni}_{3}(\mathrm{Al}$, $\mathrm{Ti}$, Ta)-type $\gamma^{\prime}$ precipitates and $\gamma$ matrix processes a strength-ductility combination both at room temperature and $700{ }^{\circ} \mathrm{C}$ (more outstanding than the performance of IN718 superalloys) and unifies the complementary advantages of commercial solid-solution- and precipitation-strengthened superalloys. Consequently, L12-strengthened CrCoNi-based 
MEAs are reasonably expected to be structural materials partly replacing commercial superalloys for potential engineering applications. Similarly, Ni-based single-crystal superalloys produced by directional solidification (DS) are suitable for engineering applications with extreme requirements due to their satisfactory high-temperature strength and outstanding creep and oxidation resistance [11-13]. The proximity of $\mathrm{CrCoNi}$-based MEAs and Nibased single-crystal superalloys in composition, performance, and applicable environment makes the joining of MEAs and single-crystal superalloys highly anticipated for engineering applications. In addition, the reliable joining of MEAs/single-crystal superalloys can achieve complementary superiorities of both materials, significantly extending the potential applications in areas such as the aviation industry, aerospace engineering, and nuclear energy engineering [14,15].

Welding, an irreplaceable metal forming method, plays a pivotal role in the practical applications of emerging HEAs and MEAs. Recently reported welding methods include fusion welding [16], friction welding [17,18], brazing [19,20], transient liquid phase bonding [15], and diffusion bonding [21-23]. Diffusion bonding, a solid-state welding technology, exhibits exceedingly good adaptability to advanced structural materials and hardly damages the performance of base metal. In particular, diffusion bonding is a priority for realizing a sound joint of dissimilar materials, which greatly relieves the problems such as poor compatibility, residual stresses, and thermal cracks [24,25]. Diffusion bonding of AlCoCrFeNi 2.1 HEA to GH4169 superalloy and TiAl alloy was completed and the microstructural characteristics and mechanical properties were reported by Li et al. [22,23]. However, diffusion bonding of HEAs (or MEAs) to Ni-based single-crystal superalloys has not yet been reported. The interfacial void closure, element diffusion characteristics, effect of bonding parameters on joint performance, and fracture behavior of diffusionbonded joints are still undefined. Therefore, detailed investigation on diffusion bonding of HEAs (or MEAs) to Ni-based single-crystal superalloys is of significant importance for accelerating the realization of engineering applications.

In this study, the diffusion bonding of CoCrNi-based medium-entropy alloy to DD5 single-crystal superalloy was performed under vacuum. The typical microstructure and microstructural evolution were investigated. The effect of diffusion bonding temperature on the joint performance was evaluated. In addition, the mechanical properties and crack propagation behavior of the joint under tensile test were elucidated.

\section{Materials and Methods}

The base materials used in this study were $(\mathrm{CoCrNi})_{94} \mathrm{Al}_{3} \mathrm{Ti}_{3} \mathrm{MEA}$ and DD5 singlecrystal superalloy. The chemical compositions of DD5 single-crystal superalloy and $(\mathrm{CoCrNi})_{94} \mathrm{Al}_{3} \mathrm{Ti}_{3} \mathrm{MEA}$ are listed in Table 1 . The $(\mathrm{CoCrNi})_{94} \mathrm{Al}_{3} \mathrm{Ti}_{3} \mathrm{MEA}$ was self-prepared by arc melting mixed high-purity (greater than 99.95 wt.\%) $\mathrm{Co}, \mathrm{Cr}, \mathrm{Ni}, \mathrm{Al}$, and Ti particles under argon protection. The $(\mathrm{CoCrNi})_{94} \mathrm{Al}_{3} \mathrm{Ti}_{3}$ ingot was remelted four times with electromagnetic stirring and then injected into a rectangular copper mold. The rectangular MEA was treated by homogenization (i.e., $4 \mathrm{~h}$ duration at $1200^{\circ} \mathrm{C}$ ) and then water-quenched. Next, the MEA was cold-rolled to the thickness reduction of $60 \%$ along the direction of suction casting. Finally, recrystallization treatment for the rolled sheet was conducted at $1150{ }^{\circ} \mathrm{C}$ for $1.5 \mathrm{~min}$ to produce equiaxed grains, followed by aging at $800{ }^{\circ} \mathrm{C}$ for $2 \mathrm{~h}$. The DD5 single-crystal superalloy was manufactured by DS along [001] orientation and was solution-treated at $1300{ }^{\circ} \mathrm{C}$ for $2 \mathrm{~h}$ followed by air cooling. Thereafter, the DD5 was aged at 1120,1080 , and $900^{\circ} \mathrm{C}$ for $4 \mathrm{~h}$ and air-cooled.

Figure 1 shows the microstructure of the $(\mathrm{CoCrNi})_{94} \mathrm{Al}_{3} \mathrm{Ti}_{3}$ and DD5 before diffusion bonding. The $(\mathrm{CoCrNi})_{94} \mathrm{Al}_{3} \mathrm{Ti}_{3}$ is composed of $\mathrm{Ni}_{3}(\mathrm{Al}, \mathrm{Ti})$-type $\gamma^{\prime}$ precipitates and $\gamma$ matrix (Figure 1a,b), consistent with that reported by Zhao et al. [9]. The DD5 contains $\gamma^{\prime}$ strengthening phase, $\gamma$ matrix, and granular carbides mainly distributed in the interdendritic zone, as shown in Figure $1 \mathrm{c}, \mathrm{d}$. The $(\mathrm{CoCrNi})_{94} \mathrm{Al}_{3} \mathrm{Ti}_{3}$ and DD5 for diffusion bonding were cut into cylinders by wire electrical discharge machining with heights of 5 and $15 \mathrm{~mm}$ respectively and both diameters of $16 \mathrm{~mm}$. All the bonding surfaces were 
polished employing 1500-grit $\mathrm{SiC}$ paper to remove oxide films. After that, the samples for diffusion bonding were ultrasonically cleaned in alcohol for $10 \mathrm{~min}$, followed by drying with cold air. Subsequently, the samples were fixed in a vacuum furnace by graphite clamps. The assembly of the sample for diffusion bonding is presented in Figure 2. The diffusion bonding processes were carried out at variable bonding temperatures of 1020, 1050,1080 , and $1110^{\circ} \mathrm{C}$ for $1 \mathrm{~h}$. A bonding pressure of $10 \mathrm{MPa}$ was applied to promote void closure, and the vacuum condition was maintained below $6 \times 10^{-3} \mathrm{~Pa}$ throughout diffusion bonding.

Table 1. Chemical composition of the DD5 single-crystal superalloy and ( $\mathrm{CrCoNi})_{94} \mathrm{Al}_{3} \mathrm{Ti}_{3} \mathrm{MEA}$ (wt.\%).

\begin{tabular}{cccccccccccccc}
\hline Base Metals & Co & Cr & Al & Ti & Ta & Hf & Mo & W & Re & B & C & Ni & \\
\hline DD5 & 7.38 & 6.96 & 6.10 & - & 6.42 & 0.14 & 1.42 & 5.02 & 3.02 & 0.003 & 0.052 & 63.485 \\
$(\mathrm{CoCrNi})_{94} \mathrm{Al}_{3} \mathrm{Ti}_{3}$ & 33.30 & 29.34 & 1.46 & 2.60 & - & - & - & - & - & - & - & 33.30 \\
\hline
\end{tabular}
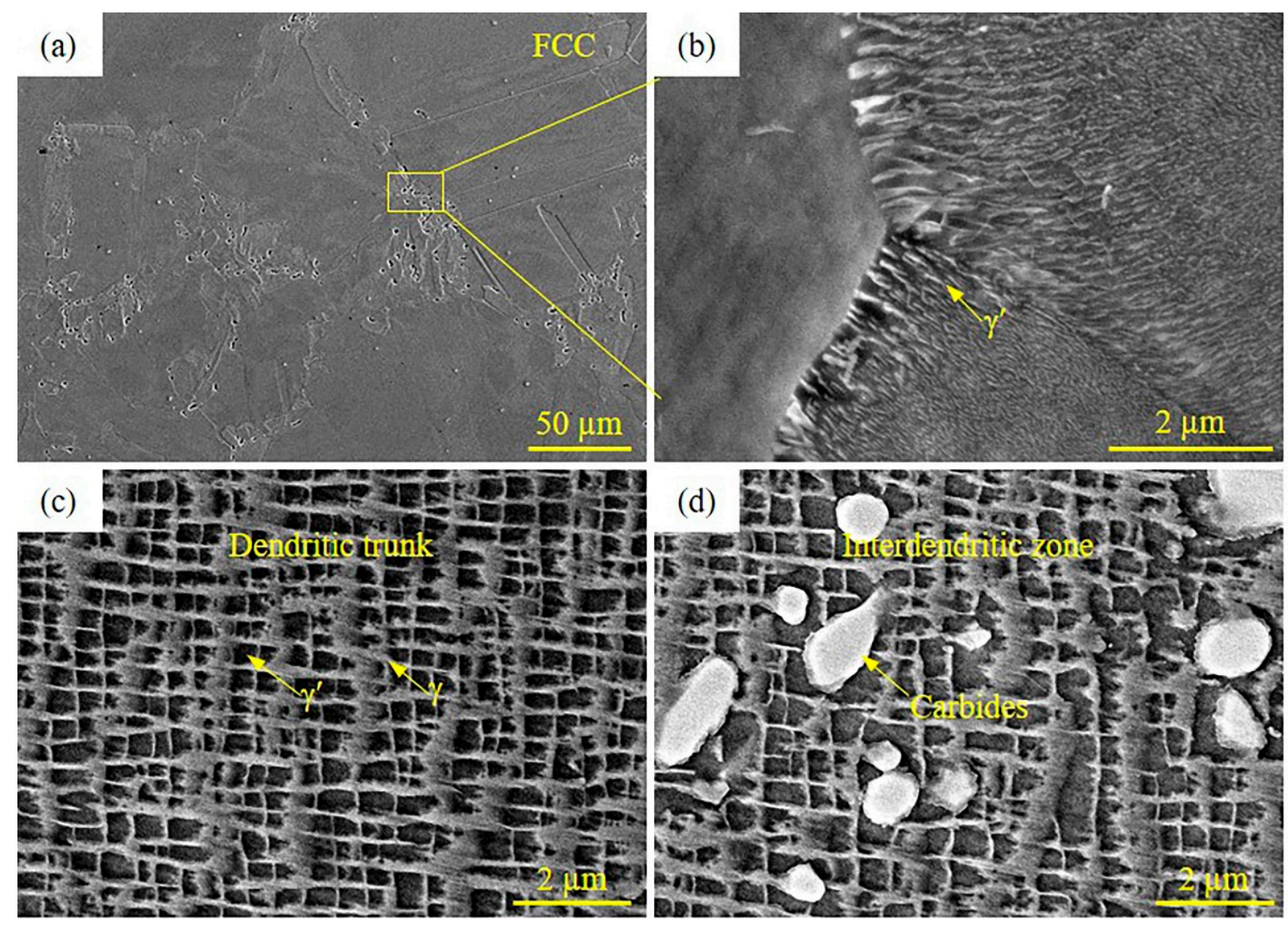

Figure 1. Microstructure of the base materials: (a) $(\mathrm{CoCrNi})_{94} \mathrm{Al}_{3} \mathrm{Ti}_{3} \mathrm{MEA}$ and (b) corresponding magnified morphology; (c) dendritic trunk and (d) interdendritic zone of DD5 single-crystal superalloy.

The microstructure of the diffusion-bonded joint was examined by scanning electron microscopy (SEM, Helios G4 CX) coupled with energy-dispersive spectroscopy (EDS). The distribution of chemical composition across the MEA/DD5 interface was detected using EDS with a $10 \mathrm{kV}$ accelerating voltage and scanning step of $0.05 \mu \mathrm{m}$. The peaks chosen for the $\mathrm{Cr}, \mathrm{Co}, \mathrm{Ni}, \mathrm{Al}$, Ti, Mo, Ta, and $\mathrm{W}$ elements were $\mathrm{K}, \mathrm{L}, \mathrm{L}, \mathrm{K}, \mathrm{K}, \mathrm{L}$, M, and $\mathrm{M}$ families, respectively. The mechanical properties of the diffusion-bonded joint were evaluated employing a universal testing machine (Instron 3382). The tensile tests were conducted with a speed of $0.5 \mathrm{~mm} / \mathrm{min}$ at room temperature. 


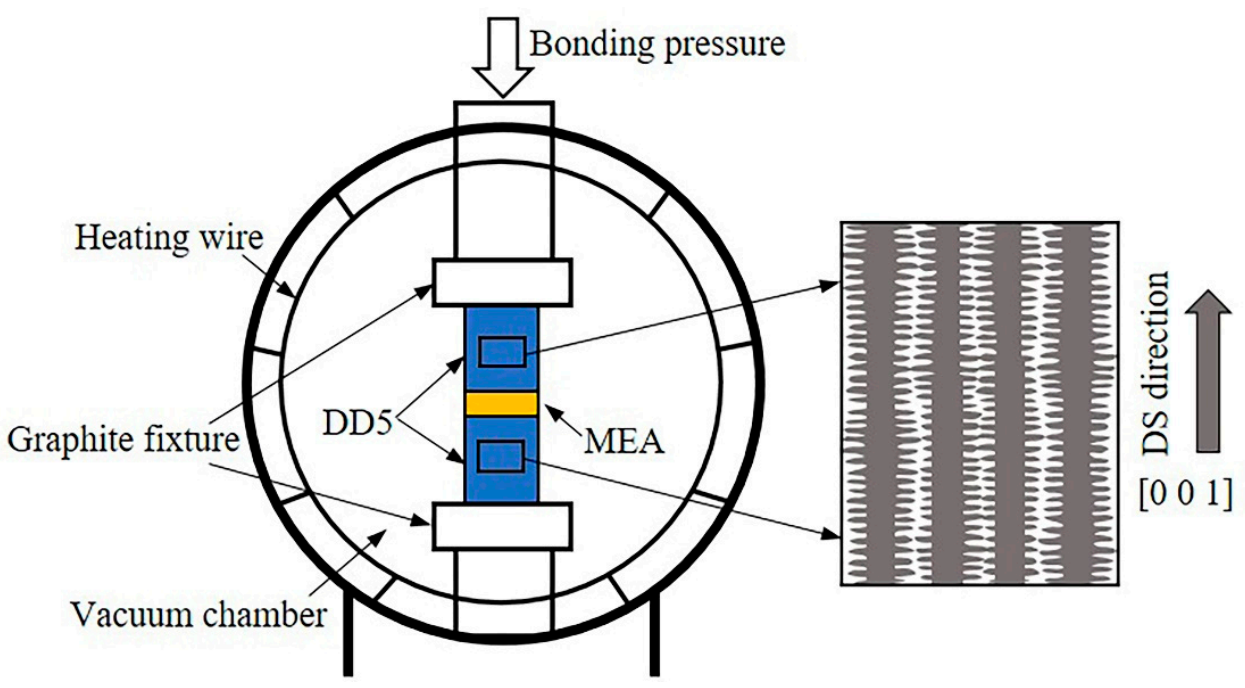

Figure 2. Sketch of the diffusion bonding assembly for $(\mathrm{CoCrNi})_{94} \mathrm{Al}_{3} \mathrm{Ti}_{3} \mathrm{MEA}$ and DD5 singlecrystal superalloy.

\section{Results and Discussion}

\subsection{Typical Microstructure of the Diffusion-Bonded MEA/DD5 Joint}

Figure 3 shows the microstructure of the $(\mathrm{CoCrNi})_{94} \mathrm{Al}_{3} \mathrm{Ti}_{3}$ MEA to DD5 single-crystal superalloy joint that was diffusion-bonded at $1110^{\circ} \mathrm{C}$ for $1 \mathrm{~h}$. The interfacial microstructure illustrates that overall a sound bonded interface without apparent cracks and voids was obtained under this condition, as shown in Figure 3a. Figure $3 \mathrm{~b}$ demonstrates the magnified photograph of the bonded interface in Figure 3a. A $6.9 \mu \mathrm{m}$ thick diffusion zone was formed due to the interdiffusion of interfacial atoms, which was conducive to the realization of reliable joining. In addition, the chemical composition variation across the diffusionbonded MEA/DD5 interface was clarified using EDS line scan, as presented in Figure 4. According to the EDS results, the matrix of the diffusion zone was mainly composed of $\mathrm{Ni}$, $\mathrm{Co}$, and $\mathrm{Cr}$, and the concentration of $\mathrm{Ni}$ was higher than that of $\mathrm{Co}$ and $\mathrm{Cr}$, allowing the MEA to be considered as Ni-rich. Simultaneously, DD5 was rich in $\mathrm{Al}$, promoting $\mathrm{Ni}_{3}(\mathrm{Al}$, Ti)-type $\gamma^{\prime}$ formation, diffused from DD5 to MEA at the bonding temperature $\left(1110{ }^{\circ} \mathrm{C}\right)$, which led to the formation of supersaturated solid solution located in the diffusion zone (Figure $4 \mathrm{~b}$ ). After diffusion bonding duration, nanoscale $\mathrm{Ni}_{3}\left(\mathrm{Al}\right.$, Ti)-type $\gamma^{\prime}$ phases labeled in Figure $3 b$ were precipitated in the diffusion zone due to a decrease in solubility with temperature reduction. The microstructure efficiently corresponds to the EDS results, which also conforms to the study of Liu et al. [14]. To be clear, the EDS profile does not represent the exact composition profile because of the interaction volume. It is also a fact that the thickness of the diffusion zone obtained by SEM (Figure 3b) effectively corresponds to that measured by EDS (Figure 4), which illustrates that the EDS result is relatively accurate.

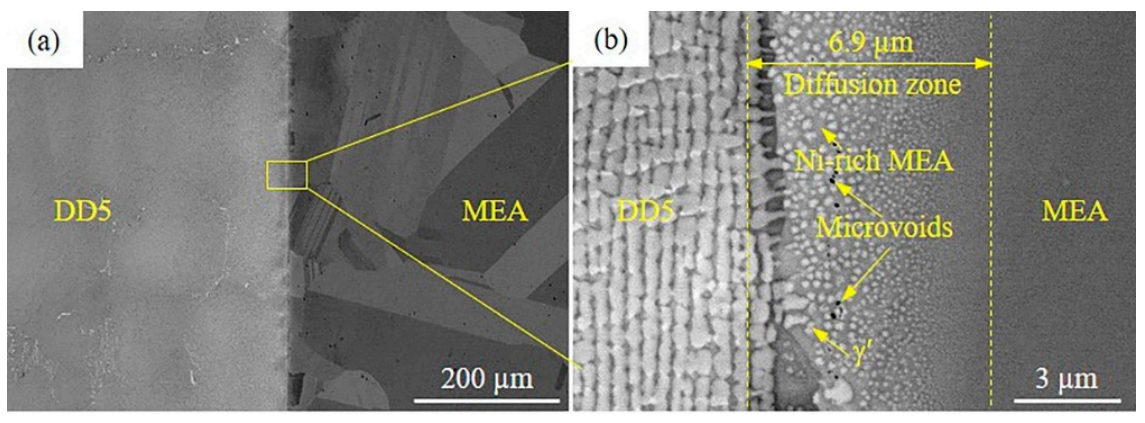

Figure 3. Microstructure of the $(\mathrm{CoCrNi})_{94} \mathrm{Al}_{3} \mathrm{Ti}_{3} \mathrm{MEA} / \mathrm{DD} 5$ single-crystal superalloy joint diffusionbonded at $1110^{\circ} \mathrm{C}$ for $1 \mathrm{~h}$ : (a) interfacial microstructure and (b) corresponding magnified photograph. 

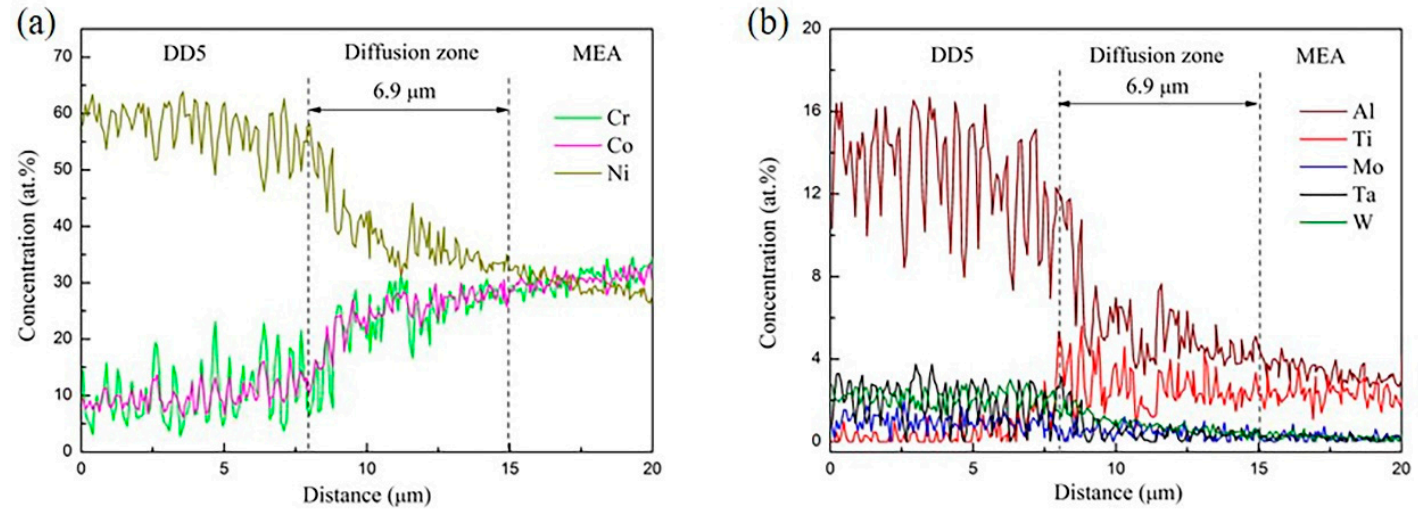

Figure 4. Chemical composition variation across the diffusion-bonded MEA/DD5 interface: (a) Cr, Co, and Ni; (b) Al, Ti, $\mathrm{Mo}, \mathrm{Ta}$, and W.

Notably, nanoscale microvoids remained in the diffusion zone of the joint diffusionbonded at $1110{ }^{\circ} \mathrm{C}$ for $1 \mathrm{~h}$, as displayed in Figure $3 \mathrm{~b}$. The microvoids were probably due to interfacial porosities (i.e., grinding and polishing imprints) not being completely closed during the bonding duration. In general, interfacial porosities are gradually compacted as a result of interfacial plastic deformation and creep under the combined action of bonding temperature and pressure. The closure of residual microvoids that cannot be compacted by plastic deformation and creep will be dominated by diffusion in the next duration at bonding temperature. If closure of microvoids is not entirely accomplished when diffusion bonding duration is completed, microvoids will remain in the interface of bonded joints [26-28]. Evidently, nanoscale microvoids resided in the bonded joint under this insufficient diffusion bonding condition for complete closure, as observed in Figure 3b.

\subsection{Effect of Bonding Temperature on the Microstructure}

Figure 5 shows the microstructure of the $(\mathrm{CoCrNi})_{94} \mathrm{Al}_{3} \mathrm{Ti}_{3} \mathrm{MEA} / \mathrm{DD} 5$ single-crystal superalloy joints that were diffusion-bonded at different bonding temperatures $(1020,1050$, and $1080{ }^{\circ} \mathrm{C}$ ) for $1 \mathrm{~h}$. Compared with the joint achieved at $1110^{\circ} \mathrm{C}$ (Figure 3), interfacial microvoids were evidently visible in the joints obtained at low bonding temperatures $\left(1020,1050\right.$, and $\left.1080^{\circ} \mathrm{C}\right)$. Reasonably, the dimension and density of microvoids decreased with the increase in bonding temperature due to high temperature reducing the resistance of plastic deformation and creep and promoting the interdiffusion of interfacial atoms. In addition, high temperature assisted the formation of the diffusion zone, principally referring to the diffusion of $\mathrm{Ni}$ and $\mathrm{Al}$ from the DD5 to the MEA and the diffusion of Co and $\mathrm{Cr}$ in the opposite direction. At high bonding temperature $\left(1110^{\circ} \mathrm{C}\right)$, a large amount of $\mathrm{Al}$ diffused to the MEA, which resulted in the formation of supersaturated solid solution in the interface region, namely the diffusion zone consisting of $\gamma^{\prime}$ participates and Ni-rich MEA (Figure 3b). On the contrary, the diffusion zone was blurred in the joints that were diffusion-bonded at low temperatures $\left(1020,1050\right.$, and $\left.1080{ }^{\circ} \mathrm{C}\right)$, as illustrated in Figure 5 . Thus, EDS line scan was performed to distinguish the interdiffusion of interfacial atoms. Figure 6 exhibits the elemental distribution across the interface of the joints diffusionbonded at 1020, 1050, and $1080{ }^{\circ} \mathrm{C}$. Diffusion zones with thicknesses of 3.0, 3.3, and $3.9 \mu \mathrm{m}$ were formed at 1020,1050 , and $1080^{\circ} \mathrm{C}$ respectively, which were significantly thinner than that of $1110^{\circ} \mathrm{C}(6.9 \mu \mathrm{m})$. Notably, some errors are inevitable for EDS results because the volume of emission of the X-rays emitted under the electron beam was ignored.

On the other hand, it is worth noting the effect of bonding temperature on the microstructural evolution of the base metals. It is reasonable to consider that the microstructure of DD5 hardly changed after the bonding processes, in which the bonding temperatures $\left(1020,1050,1080\right.$, and $\left.1110^{\circ} \mathrm{C}\right)$ were lower than that of aging treatment $\left(1120^{\circ} \mathrm{C}\right)$ and the duration $(1 \mathrm{~h})$ was shorter than the aging time $(4 \mathrm{~h})$. However, the duration at bonding temperatures led to grain coarsening of the $(\mathrm{CoCrNi})_{94} \mathrm{Al}_{3} \mathrm{Ti}_{3} \mathrm{MEA}$ in different degrees. 
The grain size of the MEA in different states is statistically summarized in Table 2. The grain was significantly coarsened to $232 \mu \mathrm{m}$ through the bonding process $(1 \mathrm{~h}$ duration at $\left.1110^{\circ} \mathrm{C}\right)$, which was approximately 3.6 times the grain size before diffusion bonding $(64 \mu \mathrm{m})$.
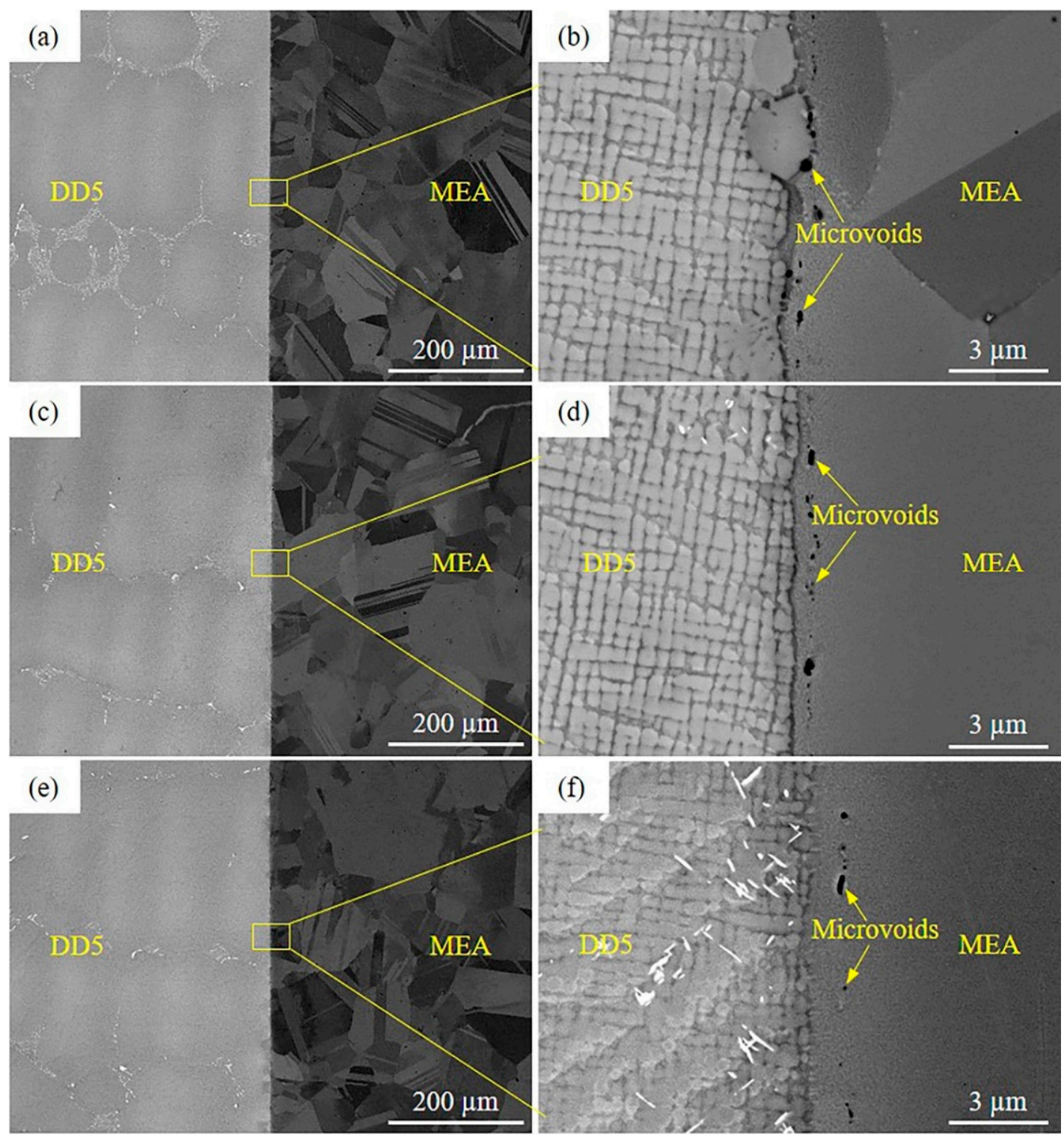

Figure 5. Microstructure of the $(\mathrm{CoCrNi})_{94} \mathrm{Al}_{3} \mathrm{Ti}_{3} \mathrm{MEA} / \mathrm{DD} 5$ single-crystal superalloy joints diffusion-bonded at different temperatures: $(\mathbf{a}, \mathbf{b}) 1020^{\circ} \mathrm{C},(\mathbf{c}, \mathbf{d}) 1050{ }^{\circ} \mathrm{C}$, and $(\mathbf{e}, \mathbf{f}) 1080^{\circ} \mathrm{C}$.

Table 2. Grain size of the $(\mathrm{CoCrNi})_{94} \mathrm{Al}_{3} \mathrm{Ti}_{3} \mathrm{MEA}$ in different states $(\mu \mathrm{m})$.

\begin{tabular}{cccccc}
\hline State of the MEA & Before Bonding & Bonded at $\mathbf{1 0 2 0}{ }^{\circ} \mathbf{C}$ & Bonded at $\mathbf{1 0 5 0}{ }^{\circ} \mathbf{C}$ & Bonded at $\mathbf{1 0 8 0}{ }^{\circ} \mathbf{C}$ & Bonded at $\mathbf{1 1 1 0}{ }^{\circ} \mathbf{C}$ \\
\hline Grain size & 64 & 95 & 104 & 123 & 232 \\
\hline
\end{tabular}


(a)

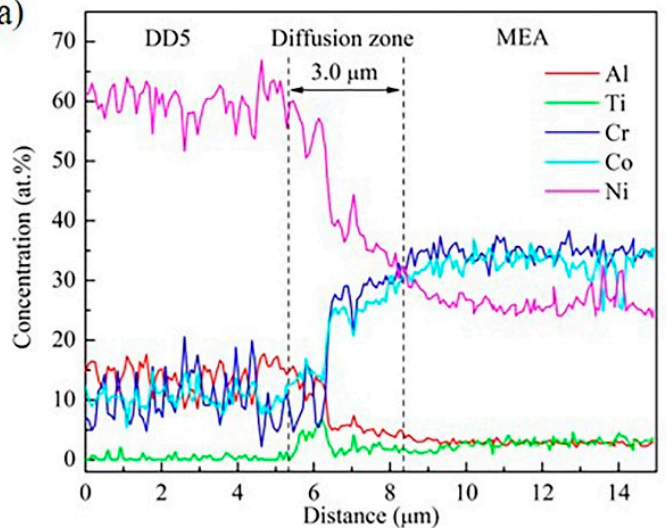

(b)

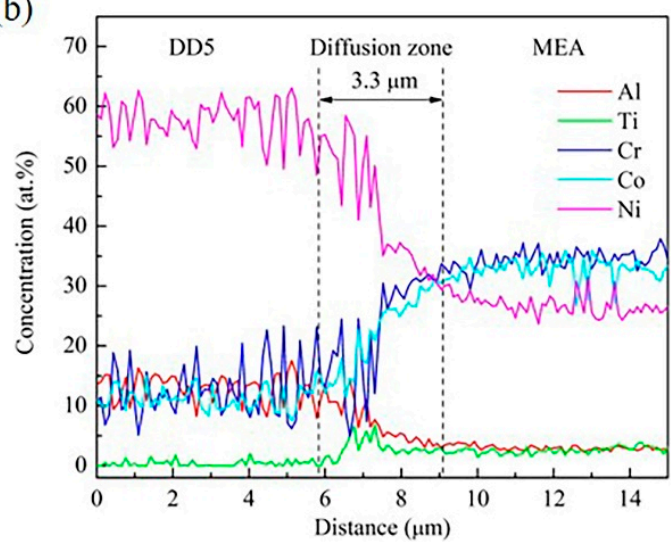

(c)

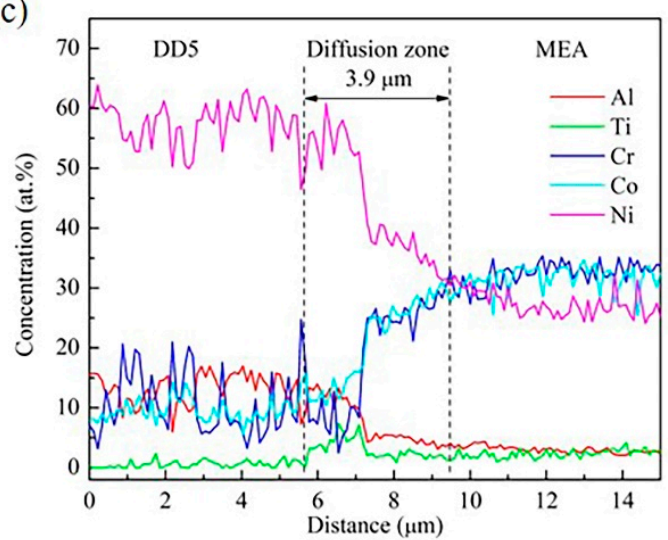

Figure 6. Distribution of chemical composition across the MEA/DD5 interface in the joints diffusion-bonded at different temperatures: (a) $1020^{\circ} \mathrm{C}$, (b) $1050{ }^{\circ} \mathrm{C}$, and (c) $1080^{\circ} \mathrm{C}$.

\subsection{Mechanical Properties of the Diffusion-Bonded MEA/DD5 Joint}

The mechanical properties of the diffusion-bonded joints were evaluated by tensile tests at $25^{\circ} \mathrm{C}$. Figure 7 shows the tensile strength and elongation of the joints diffusionbonded at different temperatures. Overall, the joints diffusion-bonded at low bonding temperatures $\left(1020,1050\right.$, and $\left.1080{ }^{\circ} \mathrm{C}\right)$ exhibit similar mechanical properties, including tensile strength and elongation. The tensile strength and elongation are $955 \mathrm{MPa}$ and $14.3 \%\left(1020{ }^{\circ} \mathrm{C}\right), 968 \mathrm{MPa}$ and $15.2 \%\left(1050^{\circ} \mathrm{C}\right), 970 \mathrm{MPa}$ and $14.9 \%\left(1080^{\circ} \mathrm{C}\right)$, respectively. Comparatively, the joint diffusion-bonded at $1110^{\circ} \mathrm{C}$ has superior tensile strength and elongation of $1045 \mathrm{MPa}$ and $22.7 \%$, as illustrated in Figure 7. The apparent microvoids and frail diffusion zones in the joints obtained at low temperatures limited the joint performance $[25,29,30]$. Both tensile strength and elongation of the joint were improved with bonding temperature elevated to $1110{ }^{\circ} \mathrm{C}$ due to high temperature promoting the elimination of microvoids and formation of a sturdy diffusion zone, which sufficiently corresponds to the above microstructural examination.

The fracture behavior and fracture mode of the diffusion-bonded joints were elucidated by macro fracture and magnified surface morphologies. The macro fracture morphologies (flat fracture) demonstrate that the propagation of crack occurred along the MEA/DD5 interface in tensile tests of the joints achieved at 1020, 1050, and $1080{ }^{\circ} \mathrm{C}$ (Figure 8a-c). The magnified morphologies of the fracture surface on the MEA side appear as small shallow dimples accompanied by embedded $\gamma^{\prime}$ particles (reasonably derived from DD5), indicating a fracture feature occurring in the interface region. Otherwise, the joint was broken in the MEA substrate under tensile load when the joint was diffusion-bonded at $1110^{\circ} \mathrm{C}$ (Figure 8d). The MEA part was considered to undergo severe plastic deformation before failure suggested by necking and fibrous zone, and typical ductile dimples were detected on the fracture surface. Consequently, the MEA substrate became the weakest part 
of the joint when the sound MEA/DD5 interface was well achieved. Notably, the tensile strength of the MEA after diffusion bonding at $1110^{\circ} \mathrm{C}$ for $1 \mathrm{~h}$ decreased compared with that of the MEA for bonding (approximately $1.3 \mathrm{GPa}$ ) [9], which was attributed to grain growth from 64 to $232 \mu \mathrm{m}$. In addition, the tensile elongation of the joint varied greatly from that of a single material sample or a conventional butt joint because the diffusion-bonded sample was assembled into a special sandwich structure.

(a)

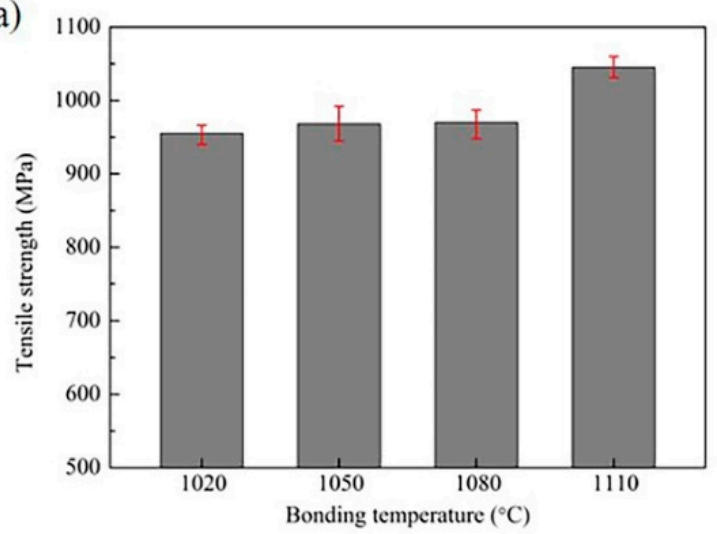

(b)

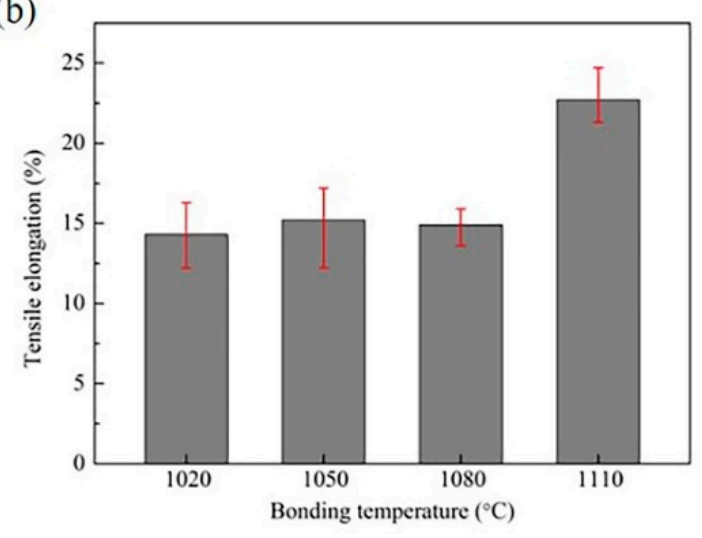

Figure 7. Tensile test results of the joints diffusion-bonded at different temperatures: (a) tensile strength and (b) elongation.
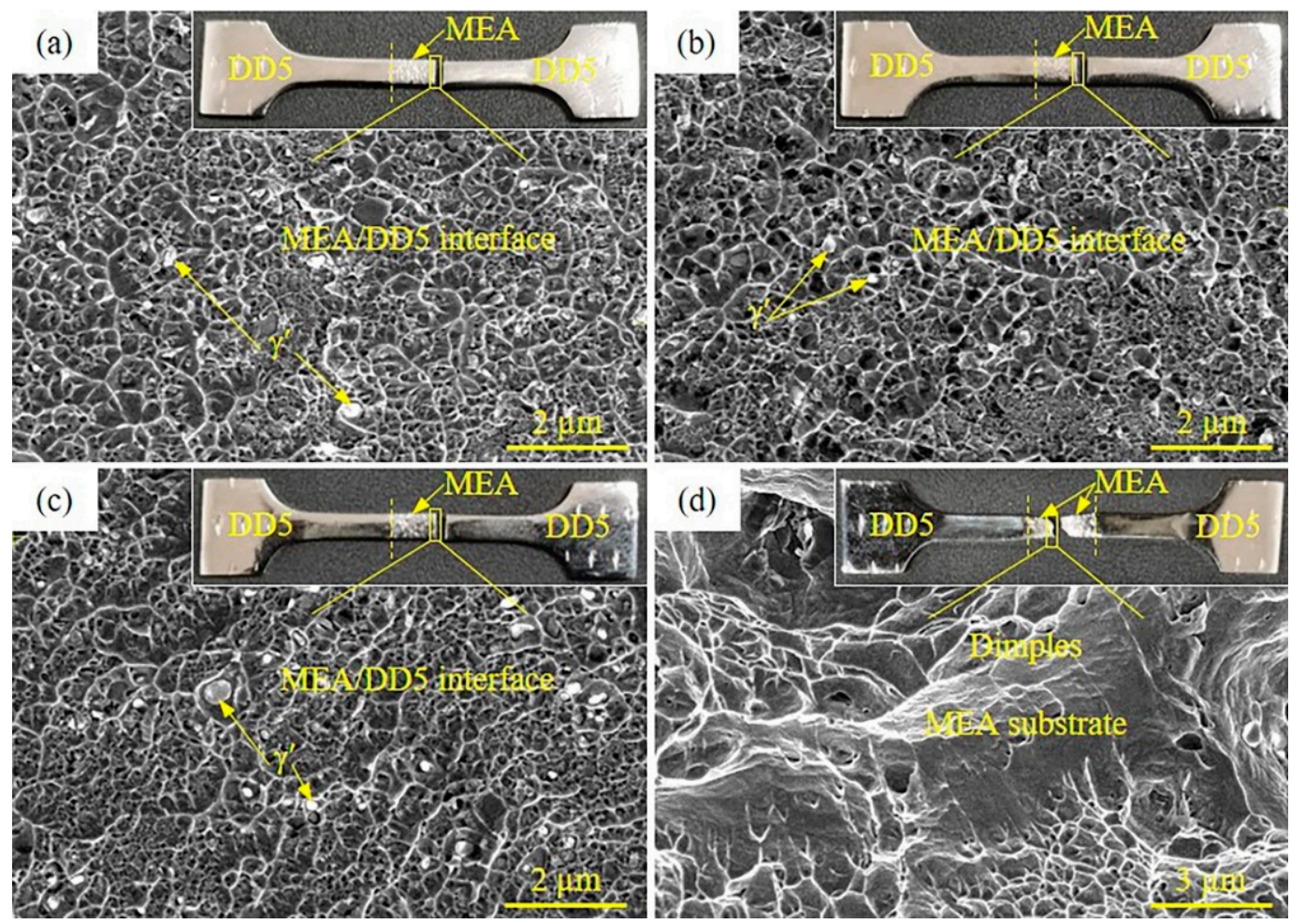

Figure 8. Macro fracture and magnified surface morphologies of the joints diffusion-bonded at $(\mathbf{a}) 1020^{\circ} \mathrm{C},(\mathbf{b}) 1050^{\circ} \mathrm{C}$, (c) $1080^{\circ} \mathrm{C}$, and (d) $1110{ }^{\circ} \mathrm{C}$.

\section{Conclusions}

In this study, the diffusion bonding of CoCrNi-based medium-entropy alloy to DD5 single-crystal superalloy was performed in a vacuum. The microstructure of the diffusionbonded joint was characterized, and the effect of bonding temperature on the microstructure was elucidated. The mechanical properties and fracture behavior of the joint were evaluated. The following conclusions can be drawn: 
(1) The typical diffusion zone with a width of $6.9 \mu \mathrm{m}$ was formed by diffusion bonding at $1110^{\circ} \mathrm{C}$ for $1 \mathrm{~h}$, achieving the reliable joining of MEA and DD5 substrates. The diffusion zone was composed of the $\mathrm{Ni}_{3}(\mathrm{Al}, \mathrm{Ti})$-type $\gamma^{\prime}$ precipitates and Ni-rich MEA matrix. In addition, nanoscale microvoids remained in the diffusion zone due to the incomplete closure of interfacial porosity.

(2) The width of the diffusion zone increased with the increase in bonding temperature; on the contrary, the size and density of interfacial microvoids decreased. Furthermore, the grain size of MEA substrate significantly grew to $232 \mu \mathrm{m}$ (diffusion-bonded at $1110{ }^{\circ} \mathrm{C}$ ), which was approximately 3.6 times that of the MEA before diffusion bonding $(64 \mu \mathrm{m})$.

(3) Both tensile strength and elongation of the joint diffusion-bonded at $1110{ }^{\circ} \mathrm{C}$ were superior to those of the joints diffusion-bonded at low temperatures $(1020,1050$, and $1080^{\circ} \mathrm{C}$ ). The maximum tensile strength of $1045 \mathrm{MPa}$ and concurrent elongation of $22.7 \%$ were achieved when the joint was diffusion-bonded at $1110^{\circ} \mathrm{C}$ for $1 \mathrm{~h}$. The typical ductile failure of the joint occurred in the MEA substrate $\left(1110^{\circ} \mathrm{C}\right)$, clearly differing from the crack propagating along the MEA/DD5 interface (low temperatures).

Author Contributions: Methodology, S.L., J.X. and J.L.; formal analysis, S.L. and Z.L.; investigation, S.L., Z.L., X.S., Y.D., Y.P. and Y.C.; writing-original draft preparation, S.L.; writing-review and editing, S.L., J.X. and J.L. All authors have read and agreed to the published version of the manuscript.

Funding: This research was funded by National Natural Science Foundation of China, Grant Nos. 51975480, 52075449, and U1737205.

Institutional Review Board Statement: Not applicable.

Informed Consent Statement: Not applicable.

Data Availability Statement: Not applicable.

Conflicts of Interest: The authors declare no conflict of interest.

\section{References}

1. Yeh, J.-W.; Chen, S.-K.; Lin, S.-J.; Gan, J.-Y.; Chin, T.-S.; Shun, T.-T.; Tsau, C.-H.; Chang, S.-Y. Nanostructured High-Entropy Alloys with Multiple Principal Elements: Novel Alloy Design Concepts and Outcomes. Adv. Eng. Mater. 2004, 6, 299-303. [CrossRef]

2. Zhang, Y.; Zuo, T.T.; Tang, Z.; Gao, M.C.; Dahmen, K.A.; Liaw, P.K.; Lu, Z.P. Microstructures and properties of high-entropy alloys. Prog. Mater. Sci. 2014, 61, 1-93. [CrossRef]

3. Miracle, D.; Senkov, O. A critical review of high entropy alloys and related concepts. Acta Mater. 2017, 122, 448-511. [CrossRef]

4. Liu, T.; Wu, Z.; Stoica, A.; Xie, Q.; Wu, W.; Gao, Y.; Bei, H.; An, K. Twinning-mediated work hardening and texture evolution in CrCoFeMnNi high entropy alloys at cryogenic temperature. Mater. Des. 2017, 131, 419-427. [CrossRef]

5. Shams, S.A.A.; Jang, G.; Won, J.; Bae, J.; Jin, H.; Kim, H.; Lee, C. Low-cycle fatigue properties of CoCrFeMnNi high-entropy alloy compared with its conventional counterparts. Mater. Sci. Eng. A 2020, 792, 139661. [CrossRef]

6. Gludovatz, B.; Hohenwarter, A.; Thurston, K.V.S.; Bei, H.; Wu, Z.; George, E.P.; Ritchie, B. Exceptional damage-tolerance of a medium-entropy alloy CrCoNi at cryogenic temperatures. Nat. Commun. 2016, 7, 10602. [CrossRef] [PubMed]

7. Zhang, Z.; Sheng, H.; Wang, Z.; Gludovatz, B.; Zhang, Z.; George, E.; Yu, Q.; Mao, S.X.; Ritchie, R.O. Dislocation mechanisms and 3D twin architectures generate exceptional strength-ductility-toughness combination in CrCoNi medium-entropy alloy. Nat. Commun. 2017, 8, 14390. [CrossRef]

8. Laplanche, G.; Kostka, A.; Reinhart, C.; Hunfeld, J.; Eggeler, G.; George, E. Reasons for the superior mechanical properties of medium-entropy CrCoNi compared to high-entropy CrMnFeCoNi. Acta Mater. 2017, 128, 292-303. [CrossRef]

9. Zhao, Y.L.; Yang, T.; Tong, Y.; Wang, J.; Luan, J.H.; Jiao, Z.B.; Chen, D.; Yang, Y.; Hu, A.; Liu, C.T.; et al. Heterogeneous precipitation behavior and stacking-fault-mediated deformation in a CoCrNi-based medium-entropy alloy. Acta Mater. 2017, 138, 72-82. [CrossRef]

10. An, N.; Sun, Y.; Wu, Y.; Tian, J.; Li, Z.; Li, Q.; Chen, J.; Hui, X. High temperature strengthening via nanoscale precipitation in wrought CoCrNi-based medium-entropy alloys. Mater. Sci. Eng. A 2020, 798, 140213. [CrossRef]

11. Li, J.; Jing, J.; He, J.; Chen, H.; Guo, H. Microstructure evolution and elemental diffusion behavior near the interface of $\mathrm{Cr}_{2} \mathrm{AlC}$ and single crystal superalloy DD5 at elevated temperatures. Mater. Des. 2020, 193, 108776. [CrossRef]

12. Li, P.; Jiang, W.; Rui, S.-S.; Yao, W.-X.; Shi, H.-J.; Han, Q.-N.; Huang, J. Effect of misorientation on the fatigue life of nickel-base single crystal superalloy DD5 at $980^{\circ} \mathrm{C}$. Int. J. Fatigue 2021, 153, 106479. [CrossRef]

13. Cai, M.; Gong, Y.; Sun, Y.; Qu, S.; Liu, Y.; Yang, Y. Experimental study on grinding surface properties of nickel-based single crystal superalloy DD5. Int. J. Adv. Manuf. Technol. 2019, 101, 71-85. 
14. Liu, J.; Cao, J.; Lin, X.; Song, X.; Feng, J. Microstructure and mechanical properties of diffusion bonded single crystal to polycrystalline Ni-based superalloys joint. Mater. Des. 2013, 49, 622-626. [CrossRef]

15. Li, S.; Li, J.; Shi, J.; Peng, Y.; Peng, X.; Sun, X.; Jin, F.; Xiong, J.; Zhang, F. Microstructure and mechanical properties of transient liquid phase bonding DD5 single-crystal superalloy to CrCoNi-based medium-entropy alloy. J. Mater. Sci. Technol. 2022, 96, 140-150. [CrossRef]

16. Wu, Z.; David, S.; Feng, Z.; Bei, H. Weldability of a high entropy CrMnFeCoNi alloy. Scr. Mater. 2016, 124, 81-85. [CrossRef]

17. Zhu, Z.; Sun, Y.; Ng, F.; Goh, M.; Liaw, P.; Fujii, H.; Nguyen, Q.; Xu, Y.; Shek, C.; Nai, S.; et al. Friction-stir welding of a ductile high entropy alloy: Microstructural evolution and weld strength. Mater. Sci. Eng. A 2018, 711, 524-532. [CrossRef]

18. Li, P.; Sun, H.; Wang, S.; Hao, X.; Dong, H. Rotary friction welding of AlCoCrFeNi2.1 eutectic high entropy alloy. J. Alloy. Compd. 2020, 814, 152322. [CrossRef]

19. Lin, C.; Shiue, R.K.; Wu, S.K.; Lin, Y.S. Dissimilar infrared brazing of CoCrFe(Mn)Ni equiatomic high entropy alloys and 316 stainless steel. Crystals 2019, 9, 518. [CrossRef]

20. Li, S.; Li, J.; Shi, J.; Du, Y.; Peng, Y.; Jin, F.; Xiong, J.; Zhang, F. Microstructure and mechanical properties of the brazed region in the AlCoCrFeNi high-entropy alloy and FGH98 superalloy joint. Mater. Sci. Eng. A 2020, 804, 140714. [CrossRef]

21. Lei, Y.; Hu, S.; Yang, T.; Song, X.; Luo, Y.; Wang, G. Vacuum diffusion bonding of high-entropy $\mathrm{Al}_{0.85} \mathrm{CoCrFeNi}_{\mathrm{alloy}}$ to TiAl intermetallic. J. Mater. Process. Technol. 2020, 278, 116455. [CrossRef]

22. Li, P.; Sun, H.; Wang, S.; Xia, Y.; Dong, H.; Wen, G.; Zhang, H. Diffusion bonding of AlCoCrFeNi $\mathrm{Al}_{2.1}$ eutectic high entropy alloy to GH4169 superalloy. Mater. Sci. Eng. A 2020, 793, 139843. [CrossRef]

23. Li, P.; Wang, S.; Xia, Y.; Hao, X.; Dong, H. Diffusion bonding of AlCoCrFeNi 2.1 eutectic high entropy alloy to TiAl alloy. J. Mater. Sci. Technol. 2020, 45, 59-69. [CrossRef]

24. Yuan, L.; Xiong, J.; Peng, Y.; Shi, J.; Li, J. Microstructure and mechanical properties in the solid-state diffusion bonding joints of $\mathrm{Ni}_{3} \mathrm{Al}$ based superalloy. Mater. Sci. Eng. A 2019, 772, 138670. [CrossRef]

25. Li, S.; Shi, J.; Xiong, J.; Peng, Y.; Ren, J.; Zhang, F.; Li, J. Microstructural characteristics and mechanical properties of WC-Co/steel joints diffusion bonded utilizing Ni interlayer. Ceram. Int. 2021, 47, 4446-4454. [CrossRef]

26. Tang, B.; Qi, X.S.; Kou, H.C.; Li, J.S.; Milenkovic, S. Recrystallization Behavior at Diffusion Bonding Interface of High Nb Containing TiAl Alloy. Adv. Eng. Mater. 2016, 18, 657-664. [CrossRef]

27. Sun, L.; Li, M. Interfacial voids, microstructure and shear strength of TC4/TC17 bond. J. Mater. Process. Technol. 2019, 270, 265-273. [CrossRef]

28. Li, S.-X.; Xuan, F.-Z.; Tu, S.-T. Fatigue damage of stainless steel diffusion-bonded joints. Mater. Sci. Eng. A 2008, 480, 125-129. [CrossRef]

29. Li, S.-X.; Xuan, F.-Z.; Tu, S.-T. In situ observation of interfacial fatigue crack growth in diffusion bonded joints of austenitic stainless steel. J. Nucl. Mater. 2007, 366, 1-7. [CrossRef]

30. Li, S.-X.; Xuan, F.-Z.; Tu, S.-T.; Yu, S.-R. Microstructure evolution and interfacial failure mechanism in 316LSS diffusion-bonded joints. Mater. Sci. Eng. A 2008, 491, 488-491. [CrossRef] 